\title{
REDUCED TISSUE OSMOLARITY INCREASES TRPV4 EXPRESSION AND PRO-INFLAMMATORY CYTOKINES IN INTERVERTEBRAL DISC CELLS
}

\author{
B.A. Walter ${ }^{1,2}$, D. Purmessur ${ }^{1}$, A. Moon ${ }^{1}$, J. Occhiogrosso ${ }^{1}$, D.M. Laudier ${ }^{1}$, A.C. Hecht ${ }^{1}$ and J.C. Iatridis ${ }^{1, *}$ \\ ${ }^{1}$ Leni \& Peter W. May Department of Orthopaedics at the Icahn School of Medicine at Mount Sinai, \\ New York, NY, USA \\ ${ }^{2}$ Department of Biomedical Engineering, The City College of New York, New York, NY, USA
}

\begin{abstract}
The mechanical behaviour and cellular metabolism of intervertebral discs (IVDs) and articular cartilage are strongly influenced by their proteoglycan content and associated osmotic properties. This osmotic environment is a biophysical signal that changes with disease and may contribute to the elevated matrix breakdown and altered biologic response to loading observed in IVD degeneration and osteoarthritis. This study tested the hypothesis that changes in osmo-sensation by the transient receptor potential vallinoid-4 (TRPV4) ion channel occur with disease and contribute to the inflammatory environment found during degeneration. Immunohistochemistry on bovine IVDs from an inflammatory organ culture model were used to investigate if TRPV4 is expressed in the IVD and how expression changes with degeneration. Western blot, live-cell calcium imaging, and qRT-PCR were used to investigate whether osmolarity changes or tumour necrosis factor $\alpha(\mathrm{TNF} \alpha)$ regulate TRPV4 expression, and how altered TRPV4 expression influences calcium signalling and pro-inflammatory cytokine expression. TRPV4 expression correlated with TNF $\alpha$ expression, and was increased when cultured in reduced medium osmolarity and unaltered with TNF $\alpha$-stimulation. Increased TRPV4 expression increased the calcium flux following TRPV4 activation and increased interleukin-1 $\beta$ (IL-1 $\beta$ ) and IL-6 gene expression in IVD cells. TRPV4 expression was qualitatively elevated in regions of aggrecan depletion in degenerated human IVDs. Collectively, results suggest that reduced tissue osmolarity, likely following proteoglycan degradation, can increase TRPV4 signalling and enhance pro-inflammatory cytokine production, suggesting changes in TRPV4 mediated osmo-sensation may contribute to the progressive matrix breakdown in disease.
\end{abstract}

Keywords: TRPV4, intervertebral disc, osmolarity, degeneration, mechanobiology.

*Address for correspondence:

James C. Iatridis

Leni \& Peter W. May Department of Orthopaedics, Box 1188

Icahn School of Medicine at Mount Sinai

New York, NY 10029, USA

Telephone Number: 1-212-241-1517

FAX Number: 1-212-876-3168

E-mail: james.iatridis@mssm.edu

\section{Introduction}

Mechanical loading plays a critical role in regulating matrix biosynthesis in multiple musculoskeletal tissues such as intervertebral disc (IVD) and articular cartilage (Chan et al., 2011; MacLean et al., 2005; Sah et al., 1989; Walsh and Lotz, 2004). One mechanism by which chondrocytes, and presumably IVD cells, sense mechanical loading is through changes in the local osmotic environment that occurs in response to loading and the subsequent activation of the transient receptor potential vallinoid-4 (TRPV4) ion channel, a calcium permeable non-selective cation channel (O'Conor et al., 2014). The TRPV4 ion channel regulates many cellular functions in response to changes in osmolarity in other tissues (Guilak et al., 2010; Liedtke and Friedman, 2003) and was recently demonstrated to regulate the metabolic response to dynamic loading in chondrocytes (O'Conor et al., 2014). The healthy IVD has a high osmotic environment $\left(\sim 434 \mathrm{mOsm} / \mathrm{kgH}_{2} 0\right)$ compared to other tissues (Johnson et al., 2014) and experiences diurnal fluctuations in osmolarity that occur as proteoglycans within the IVD become compacted and water is exuded under compression loading. These loadinginduced osmotic fluctuations are thought to be important for regulating cellular metabolism, including aggrecan synthesis, in IVD cells and chondrocytes (Ishihara et al., 1997; Neidlinger-Wilke et al., 2012; Palmer et al., 2001). However, the mechanism through which IVD cells sense changes in their local osmotic environment remains unknown. Given the importance of tissue osmolarity in the IVD microenvironment and homeostasis, it is critical to understand how IVD cells sense changes in tissue osmolarity and whether TRPV4 is involved.

The biologic response to physiologic loading changes in multiple musculoskeletal diseases, and becomes more catabolic with the progression of osteoarthritis and IVD degeneration (Salter et al., 2002). In the IVD, physiologic loading induces an anabolic response in healthy IVD tissue and cells through increasing gene expression of matrix genes (aggrecan and collagen) and decreasing gene expression of catabolic enzymes (matrix metalloproteinases (MMPs) and ADAMTS family members) (Chan et al., 2011; Walsh and Lotz, 2004; Wuertz et al., 2009). However, this 'healthy' or remodelling response to physiologic loading is altered when the same loading conditions are applied to tissues or cells from degenerated IVDs with a tendency towards a catabolic response (Gilbert et al., 2011; Gilbert et al., 2010; Le Maitre et al., 2009; Sowa et al., 2012). Changes in mechanotransduction, i.e. how cells perceive and respond to their mechanical environment, and the consequential alterations in cellular sensitivity to mechanical loading 
may be a mechanism mediating this aberrant response. Especially, as changes in mechanotransduction are thought to play a role in the pathogenesis of several diseases, including muscular dystrophy, deafness, kidney disease and premature aging (Jaalouk and Lammerding, 2009). One of the earliest and most dramatic changes to the IVD with degeneration is the loss of proteoglycans within the nucleus pulposus (Roughley et al., 2002) and a concomitant loss of osmotic pressurisation (Urban and McMullin, 1988). This suggests that changes in osmotically regulated mechanotransduction may occur within the IVD as degeneration progresses. However, there is remarkably little information available on how IVD cell mechanotransduction is altered in disease.

Osteoarthritis and IVD degeneration involve a proinflammatory component, which contributes to matrix breakdown and associated pain (Goldring and Otero, 2011; Risbud and Shapiro, 2014). The inflammatory environment within these tissues influences the biologic response to mechanical loading (Sowa and Agarwal, 2008; Torzilli et al., 2010). However, the mechanisms underlying this interaction remain unknown. An improved understanding of the interaction between inflammation and mechanical loading may inform how inflammation arises within the tissue in early stages of disease. Adverse mechanical loading of IVD cells and tissue is known to induce the local expression of pro-inflammatory cytokines (Gawri et al., 2014; Walter et al., 2011). Nucleus pulposus (NP) tissue cultured under free swelling conditions increased prostaglandin and interleukin-6 (IL-6) expression (van Dijk et al., 2015), suggesting that changes in tissue osmolarity may influence pro-inflammatory cytokine expression. However, the mechanism mediating this response remains unclear.

The overall hypothesis of this study was that changes in osmo-sensation by the TRPV4 ion channel occur with disease and contribute to the altered mechanobiology and inflammatory environment found during degeneration. The aims of this study were (1) to determine if the TRPV4 ion channel is present in the IVD and if expression of the TRPV4 ion channel changes in an IVD degeneration model, and (2) to determine how altered TRPV4 expression and activity influences TRPV4 calcium signalling and proinflammatory cytokine expression.

\section{Materials and Methods}

Cell and organ culture techniques, using bovine and human spinal tissues, were applied with western blot, immunohistochemistry, qRT-PCR and live cell calcium imaging investigations to assess the role of TRPV4 in the IVD and its relationship with IVD degeneration. Specifically, immunohistochemistry was used to confirm the presence of TRPV4 in the bovine and human IVD tissue. A bovine inflammatory IVD organ culture model was used to identify changes in TRPV4 expression in a simulated degeneration model and bovine cell culture investigated whether tumour necrosis factor $\alpha(\mathrm{TNF} \alpha)$ or osmolarity influenced TRPV4 protein expression. Calcium imaging was used with bovine cell culture experiments to verify if TRPV4 ion channel was functional and to determine if elevated TRPV4 expression resulted in increased calcium signalling. Lastly, quantitative RT-PCR was used to investigate if TRPV4 signalling influenced pro-inflammatory cytokine gene expression.

\section{Cell culture}

Bovine nucleus pulposus (NP) and annulus fibrosus (AF) cells were isolated as previously described (Abbott et al., 2012). Briefly, three caudal IVDs (caudal levels c1-2 through c3-4) were extracted from each tail, the NP and AF tissues were separated, and the tissues from each tail pooled. The ' $n$ ' for all cell culture experiments represents the number of different animals. For TNF $\alpha$ experiments, bovine NP cells were cultured in basal medium (high glucose Dulbecco's modified Eagle medium (DMEM), $10 \%$ foetal bovine serum (FBS), $50 \mu \mathrm{g} / \mathrm{mL}$ ascorbic acid, $1 \%$ penicillin/streptomycin) or basal medium with one of three doses $(0.1,1$ or $10 \mathrm{ng} / \mathrm{mL})$ of bovine $\mathrm{rTNF} \alpha$ (Cat.\# RBOTNFAI, Thermo Scientific, Rockford, IL, USA) for $24 \mathrm{~h}$. For osmotic experiments, bovine NP cells were cultured in one of three osmotically active solutions $\left(234,334\right.$ or $\left.434 \mathrm{mOsm} / \mathrm{kgH}_{2} \mathrm{O}\right)$ for either 24 or $72 \mathrm{~h}$. Osmotically active solutions were measured using a freezing point depression osmometer (Advanced Wide-Range Osmometer 3W2, Advanced Instruments Inc., Needham Heights, MA, USA) and made by either adding $1 \mathrm{M}$ sucrose or distilled water to basal medium as previously described (Chen et al., 2002; O'Conor et al., 2014) to within $\pm 2 \mathrm{mOsm} / \mathrm{kgH}_{2} \mathrm{O}$ of the desired osmolality.

\section{Organ culture}

To investigate if expression of the TRPV4 ion channel is altered in an inflammatory environment, simulating disease, we used a previously developed inflammatory organ culture model (Walter et al., 2015a). Bovine tails were collected from a local abattoir (Green Village Packing Company, Green Village, NJ, USA) and IVDs were exposed by bulk dissection of surrounding tissue. Eight bovine caudal IVDs were isolated with intact vertebral endplates retained. IVDs were assigned to one of two groups; Control $(n=4)$ and TNF $\alpha(n=4)$. Control IVDs were cultured at $37^{\circ} \mathrm{C}$ and $5 \% \mathrm{CO}_{2}$ under dynamic loading ( $8 \mathrm{~h}: 0-0.8 \mathrm{MPa}$ at $0.1 \mathrm{~Hz} ; 16 \mathrm{~h}: 0.2 \mathrm{MPa}$ ) and the culture medium was changed every 3 to $4 \mathrm{~d}$. Control medium consisted of high glucose DMEM, $10 \%$ FBS, $50 \mu \mathrm{g} / \mathrm{mL}$ ascorbic acid, $1 \%$ penicillin/streptomycin, $0.5 \%$ fungizone (Fisher-Scientific, Waltham, MA, USA), and 1:500 primocin (Invivogen, San Diego, CA, USA), and the TNF $\alpha$ group was cultured in control medium $+100 \mathrm{ng} / \mathrm{mL}$ human recombinant TNF $\alpha$ (Invitrogen, Carlsbad, CA, USA. PHC3016). TNF $\alpha$ was chosen as the pro-inflammatory cytokine to simulate the inflamed environment present in IVD degeneration because it is expressed following tissue injury (Ulrich et al., 2007), is associated with chronic painful conditions of the spine, and is considered an initiator of a larger pro-inflammatory and catabolic cascade in the IVD (Millward-Sadler et al., 2009). Human TNF $\alpha$ was used to differentiate exogenously transported TNF $\alpha$ from endogenously expressed bovine TNF $\alpha$; however, the high homology between bovine and 
human TNF $\alpha$ prevented such differentiation. The high homology between bovine and human TNF $\alpha$ is evident in prior studies where treatment of bovine IVDs with human $\mathrm{TNF} \alpha$ resulted in catabolic changes to the IVD, including upregulation of bovine pro-inflammatory cytokines (IL-6 and IL-8) and significant proteoglycan degradation which was substantial enough to alter IVD mechanics (Purmessur et al., 2013; Walter et al., 2015a). Following culture, a central sagittal strip of tissue ( $\sim$ mm wide) was taken for histology.

\section{Immunohistochemistry and immunofluorescence}

Immunofluorescence specific for TNF $\alpha$ and immunohistochemistry for TRPV4 was performed on consecutive histologic sections from all cultured bovine caudal IVDs to quantify the degree of TNF $\alpha$ penetration and its relationship to changes in TRPV4 expression. All samples (bovine and human) were processed, embedded in methyl methacrylate (MMA) and sagittally sectioned $(5 \mu \mathrm{m})$ as previously described (Laudier et al., 2007). Prior to staining, all samples were deplasticised. For TRPV4 staining all samples were stained with a primary rabbit anti-TRPV4 ion-channel antibody (1:300, bs-6425R, Bioss Antibodies, Woburn, MA, USA) and a horse anti-rabbit horseradish peroxidase (HRP) secondary (ImmPRESS, Vector, Burlingame, CA, USA) and counter stained with Toluidine blue. For TNF $\alpha$ staining, all bovine caudal IVDs were stained with a polyclonal rabbit-anti human TNF $\alpha$ antibody (1:100 ab66579, Abcam, Cambridge, MA, USA) with a goat anti-rabbit Alexafluor 594 secondary antibody (1:700 ab150092) and counter stained with 4',6-diamidino2-phenylindole (DAPI). For all samples, negative controls were treated with non-immune rabbit serum in place of the primary antibody. The percentage of positively stained cells in the NP region was calculated from eight, $20 \times$ magnification, images using ImageJ.

Immunohistochemistry was also performed on human lumbar IVDs $(n=2)$ tissue to investigate the presence of TRPV4 in different regions of the IVD and to investigate if TRPV4 expression was differentially expressed in healthy and degenerated IVD tissue. For human staining, a degeneration score was assigned using a previously developed degeneration scoring system which ranges from 0 (healthy) to 10 (severe degeneration) (Walter et al., 2015b), modified from the Rutges scoring system (Rutges et al., 2013). Images from the NP and AF region of a healthy 44 year-old (degeneration score 2) IVD and a degenerated 93 year-old IVD (degeneration score 8 ) were taken at $20 \times$ using standard bright field microscopy and at $40 \times$ under polarised light microscopy. All images were qualitatively assessed for the number of cells expressing TRPV4. Human IVD tissue was also stained with picrosirius red and alcian blue, as previously described (Walter et al., 2015b), in order to qualitatively assess proteoglycan content.

\section{Western blot}

Western blots specific for TRPV4 were conducted on protein isolated from bovine NP cells cultured in monolayer and treated with (i) increasing doses of bovine recombinant $\mathrm{TNF} \alpha$ ( $n=3$ /group, $0,0.1,1$ and $10 \mathrm{ng} / \mathrm{mL}$ ) made in basal medium (334 mOsm $/ \mathrm{kgH}_{2} \mathrm{O}$ ) or (ii) varying osmotic media
(234 mOsm $\left./ \mathrm{kgH}_{2} 0,334 \mathrm{mOsm} / \mathrm{kgH}_{2} 0,434 \mathrm{mOsm} / \mathrm{kgH}_{2} 0\right)$ for $24 \mathrm{~h}$ ( $n=6 /$ group) or $72 \mathrm{~h}$ ( $n=3 /$ group). Cells were enzymatically released, rinsed in pre-chilled phosphatebuffered saline (PBS) and lysed in $1 \mathrm{~mL}$ of RIPA buffer. A western blot specific for the TRPV4 ion channel (1:500; bs-6425R) and $\beta$-actin (1:7500; ab8227) was conducted using a wet tank blotting system (Bio-Rad Laboratories, Hercules, CA, USA). All lanes were loaded with equal amounts of protein $(10 \mu \mathrm{g})$. Relative quantification was conducted by densitometry measurements using ImageJ software and results are presented as TRPV4 normalised to $\beta$-actin.

\section{Live cell calcium imaging}

Fura-2 ratiometric calcium imaging was used to quantify how increased TRPV4 expression influenced TRPV4 mediated calcium signalling in response to a triggering event. Bovine NP cells were seeded in a circular live cell imaging dish (Cat.\#04200417B, Fisher Scientific, Waltham, MA, USA) at a density of $\sim 7,000$ cells $/ \mathrm{cm}^{2}$ and cultured in either 334 or $434 \mathrm{mOsm} / \mathrm{kgH}_{2} 0$ culture medium for $24 \mathrm{~h}$ prior to imaging in order to induce changes in TRPV4 expression. On the day of the experiment, cells were loaded with the calcium sensitive fluorescent dye, Fura-2AM (Invitrogen \#F-1201) by incubating cells with the dye loading solution consisting of $2 \mu \mathrm{M}$ Fura-2AM dye, and an equal volume of Pluronic acid (Invitrogen Cat.\# P6867) in Hanks' Balanced Salt Solution (HBSS) for $45 \mathrm{~min}$ at $37^{\circ} \mathrm{C}$ and then rinsed with HBSS. All calcium imaging experiment were conducted at $37{ }^{\circ} \mathrm{C}$ using heated glass culture dishes and images were acquired at $20 \times$ magnification using an Olympus-IX-70 microscope by means of subsequent fluorescent images captured at $340 \mathrm{~nm}$ and $380 \mathrm{~nm}$. All NP cells were recorded for $1 \mathrm{~min}$ to obtain a baseline measurement and were then treated with a TRPV4 specific agonist, GSK1016790A (GSK101, Cat.\# G0798, 5 nM, Sigma-Aldrich, St. Louis, MO, USA) to trigger the opening of the TRPV4 channels or HBSS as a control. The ratiometric calcium measurements (340/380 ratios) were determined for every cell in the field of view using ImageJ (approximately 20-40 cells per group per experiment) and each experimental condition was repeated three times in different cell preparations from the same bovine tail. The magnitude of the calcium response was assessed after the response had come to equilibrium between 150-250 s. The magnitude of the response for each cell in both control and GSK groups was normalised to the average of the osmotically matched control and the normalised values were analysed.

\section{Quantitative real time-PCR}

A repeated measure design was used to investigate if altered TRPV4 expression/activity influenced the expression of pro-inflammatory cytokines. Bovine NP cells ( $n=3$ /group), representing cells from three separate animals, were pre-cultured in monolayer in either 334 or $434 \mathrm{mOsm} / \mathrm{kgH}_{2} \mathrm{O}$ for $24 \mathrm{~h}$. Following pre-culture, cells were treated either with or without a TRPV4 antagonist (GSK205, Cat.\# 616522, EMD Millipore, Danvers, MA, USA) for $24 \mathrm{~h}$ after which RNA was isolated using the RNeasy Kit (Qiagen, Valencia, CA, USA) following the 
a

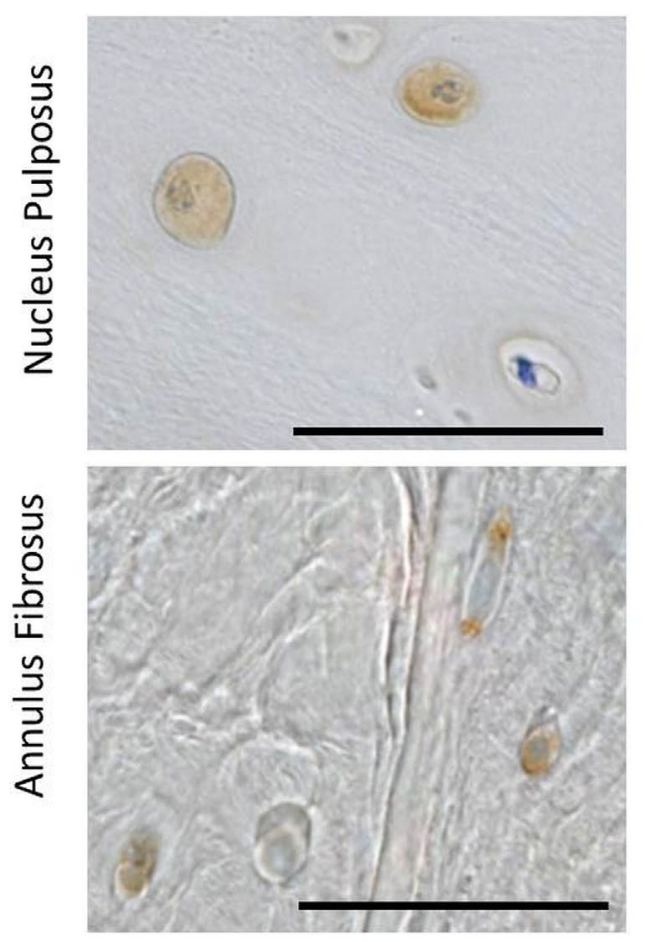

b
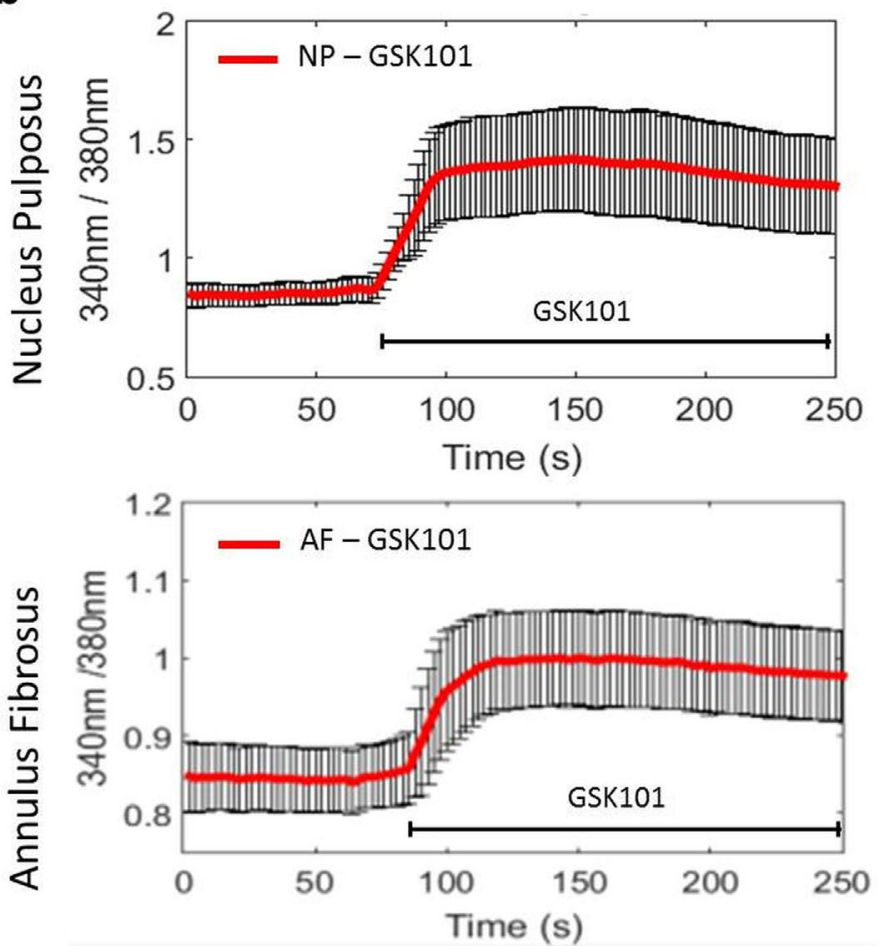

Fig. 1. TRPV4 is expressed and functional in the IVD. (a) Immunohistochemistry for TRPV4 in the nucleus pulposus (NP) and annulus fibrosus (AF) regions of bovine caudal IVDs. Positive immunostaining appears brown. (b) Calcium traces of bovine NP and AF cells in response to the TRPV4 specific agonist GSK101 confirming the presence and functionality of the TRPV4 ion channels. Scale bar $=100 \mu \mathrm{m}$.

manufacturer's instructions. RNA was quantified using a Nanodrop and equal amounts of RNA were synthesised into cDNA using the SuperScript ${ }^{\circledR}$ VILO kit (Inivtrogen, Carlsbad, CA, USA). Gene expression was quantified using human TAQMAN primers specific for IL- $1 \beta$ and IL- 6 and the housekeeping gene $18 \mathrm{~S}$. Results were analysed using the $\Delta \Delta \mathrm{C}_{\mathrm{T}}$ method (Livak and Schmittgen, 2001).

\section{Statistics}

For the organ culture experiments a Pearson's correlation coefficient was used to determine if there was a significant correlation between the percentages of cells expressing TNF $\alpha$ and TRPV4. For western blots, a repeated measures one-way ANOVA with a Tukey post-hoc test was used to compare the effects of TNF $\alpha$ concentration or medium osmolarity on TRPV4 expression. For qRTPCR experiments, a repeated measures one-way ANOVA with a Tukey post-hoc test was used to compare the pro-inflammatory gene expression between the baseline (434 mOsm $/ \mathrm{kgH}_{2} \mathrm{O}$ ), reduced osmolarity (343 mOsm/ $\mathrm{kgH}_{2} \mathrm{O}$ ) and reduced osmolarity with TRPV4 antagonist (343 $\mathrm{mOsm} / \mathrm{kgH}_{2} \mathrm{O}+\mathrm{GSK} 205$ ) groups. For the calcium imaging analysis, a non-parametric Mann-Whitney test was used to compare the normalised magnitude of the calcium wave between the 334 control and 334 GSK101 groups, 434 control and 434 GSK101 groups, and the 334 GSK101 and 434 GSK101 groups. All statistical analyses were conducted using Prism GraphPad with $p<0.05$ considered significant and $p<0.1$ considered a trend, and results are presented as mean \pm standard deviation.

\section{Results}

\section{Expression of TRPV4 in the intervertebral disc}

Immunohistochemistry on bovine caudal IVDs demonstrated that the TRPV4 ion channel was expressed by cells in both the NP and AF regions (brown staining, Fig. 1a). Intracellular $\mathrm{Ca}^{2+}$ measurements were carried out to test functional expression of TRPV4 in primary bovine NP and AF cells exposed to the TRPV4 specific agonist GSK1016790A(GSK101, 5 nM). Monitoring intra-cellular calcium concentrations in Fura-2-loaded NP and AF cells showed a significant increase in intra-cellular calcium in response to treatment with TRPV4 agonist GSK101 (Fig. 1b). Results demonstrated that the osmo-sensitive TRPV4 ion channel is expressed in NP and AF cells throughout the IVD.

\section{TRPV4 expression is correlated with TNF $\alpha$ expression in a whole IVD inflammatory organ culture model}

A bovine whole IVD inflammatory organ culture model simulating IVD degeneration was used to investigate whether there were any changes in TRPV4 expression with degeneration. Bovine caudal IVDs with intact vertebral endplates were cultured for $6 \mathrm{~d}$ with or without human recombinant TNF $\alpha(100 \mathrm{ng} / \mathrm{mL})$ supplemented into the culture medium. IVDs were dynamically loaded to promote inward TNF $\alpha$ transport (Fig. 2a). After $6 \mathrm{~d}$ of culture there was positive staining for TNF $\alpha$ and TRPV4 in the NP of all samples (Fig. $2 \mathbf{b}$ and $\mathbf{c}$ ). There was a significant 


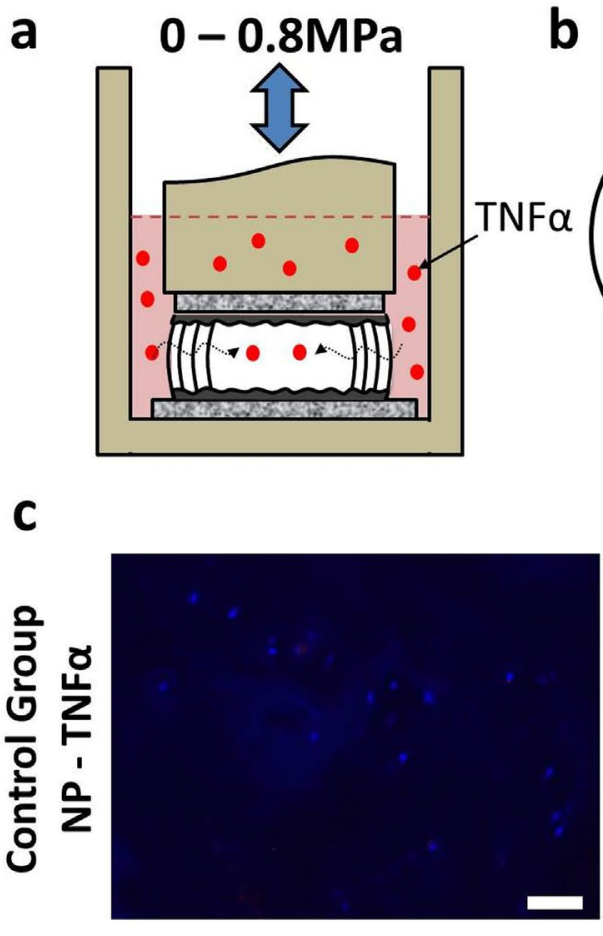

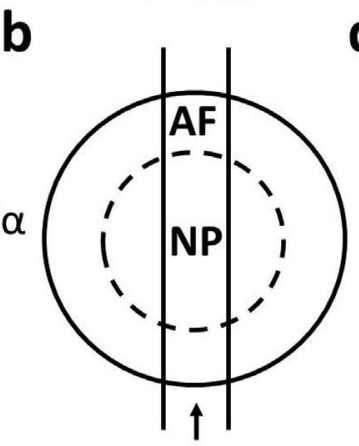

Histology
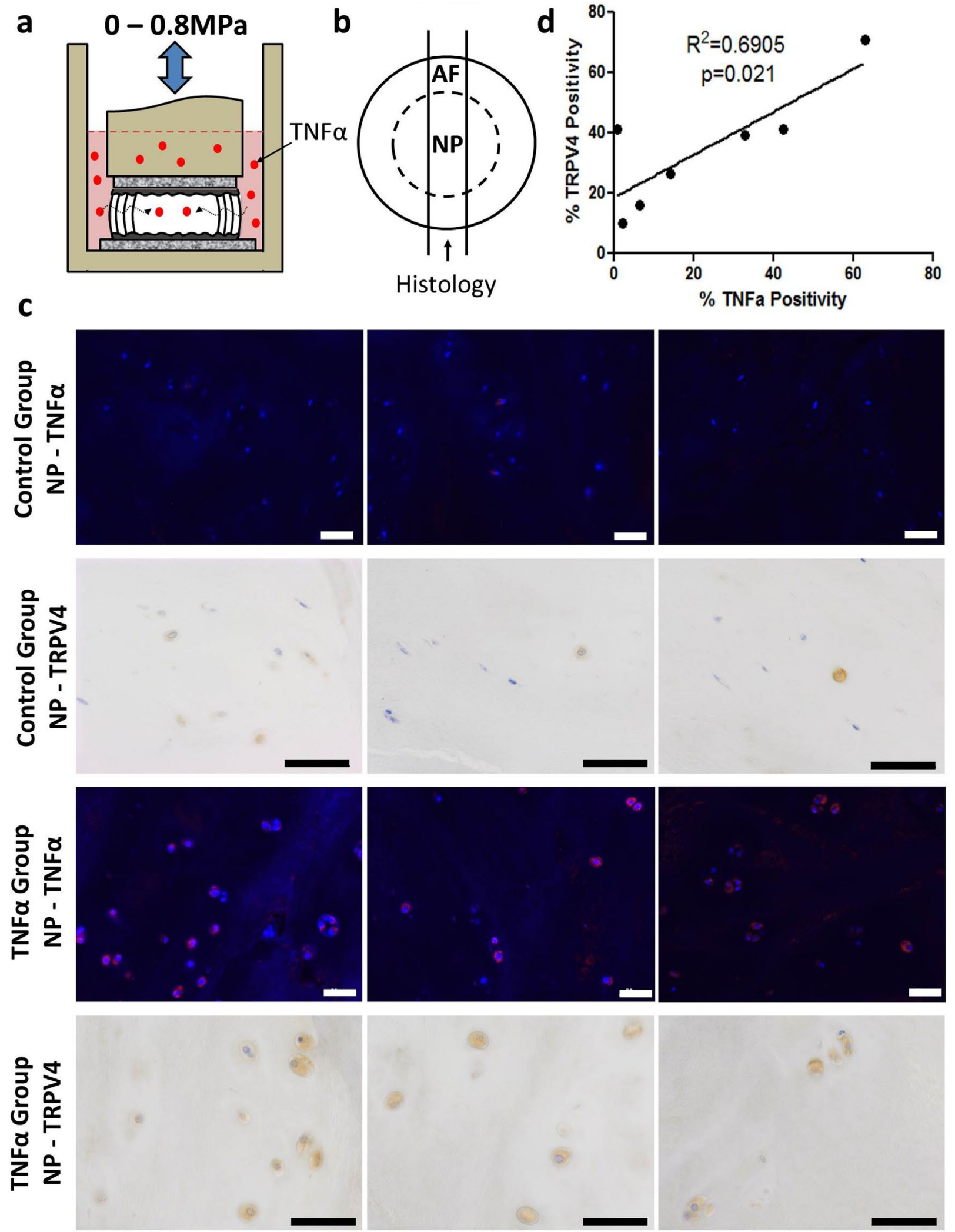

Fig. 2. TRPV4 is correlated with TNF $\alpha$ expression in an IVD organ culture model of inflammatory degeneration. (a) Schematic of the experimental set-up of the bovine whole IVD organ culture model of degeneration involving TNF $\alpha$ stimulation. (b) Schematic of the transverse cross-section of the IVD demonstrating the location of tissue used for immunohistochemistry and immunofluorescence. (c) Immunohistochemical and immunofluorescence staining for TNF $\alpha$ and TRPV4, respectively, in the nucleus pulposus region of the control and TNF $\alpha$ groups. The images in each row are from the same tissue but a different area within each region; scale bar $=50 \mu \mathrm{m}$. Staining showed greater TNF $\alpha$ and TRPV4 expression in the TNF $\alpha$-treated group. (d) There was a significant correlation between TNF $\alpha$ and TRPV4 positive cells demonstrating a relationship between TNF $\alpha$ and TRPV4 expression in the IVD. Rabbit control $\mathrm{IgG}$ antibody used as a negative control. 

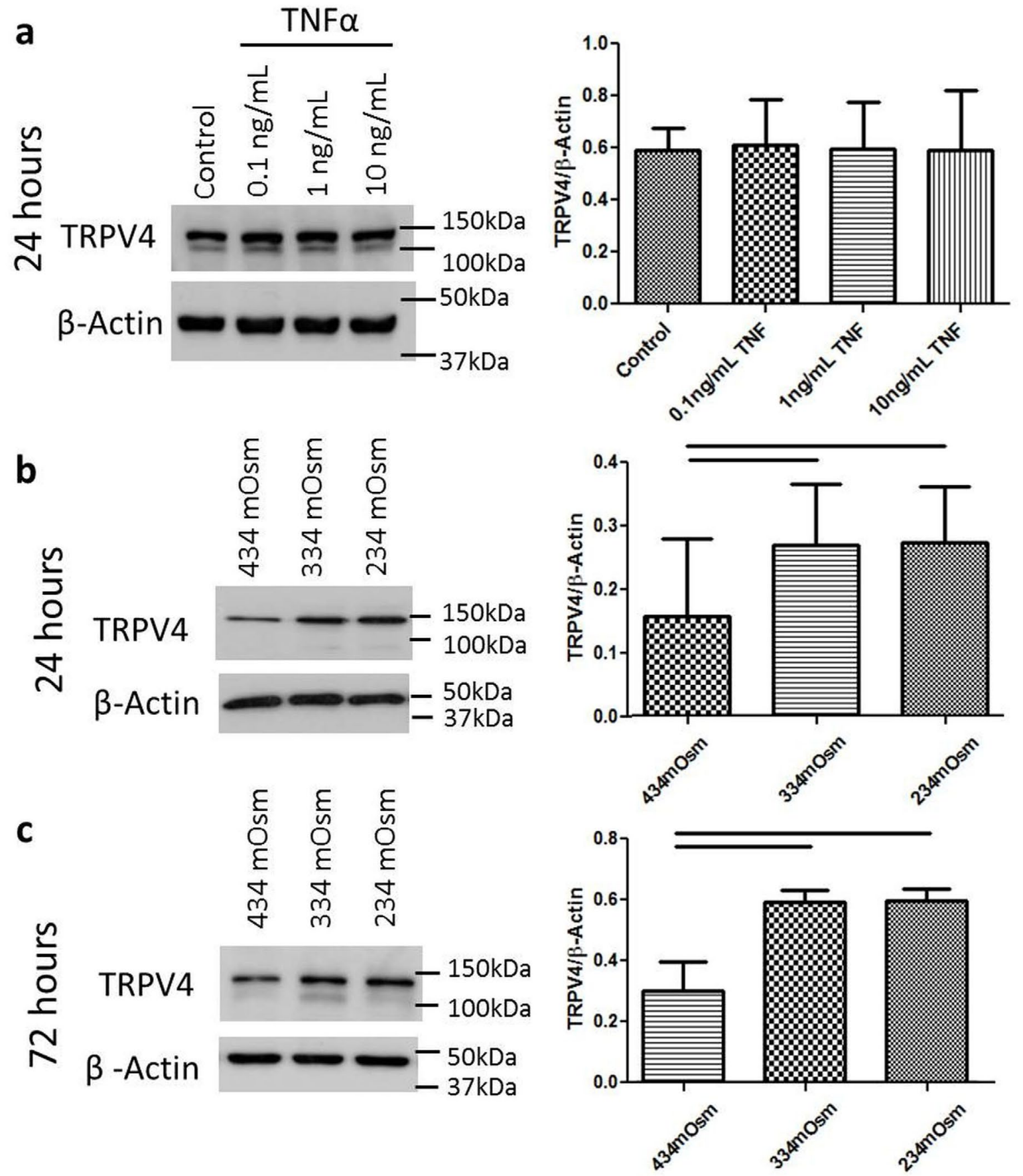

Fig. 3. Hypo-osmotic environment but not TNF $\alpha$ increased TRPV4 expression in NP cells. (a) Western blot for TRPV4 in bovine NP cell culture experiments demonstrated no change in TRPV4 expression after $24 \mathrm{~h}$ of exposure to varying doses of TNF $\alpha$. TRPV4 protein expression was increased when cultured for (b) $24 \mathrm{~h}$ and (c) $72 \mathrm{~h}$ in a reduced media osmolarity compared to the physiologic osmotic environment within the IVD $\left(\sim 434 \mathrm{mOsm} / \mathrm{kgH}_{2} \mathrm{O}\right)$. Together, results suggest that increased TRPV4 expression observed in the organ culture model was due to reduced tissue osmolarity associated with $\mathrm{TNF} \alpha$-induced aggrecan degradation and not a direct result of TNF $\alpha$ stimulation. $\mathrm{Bar}=p<0.05$.

correlation $\left(R^{2}=0.69 / p=0.02\right)$ between the $\% \mathrm{TNF} \alpha$ positivity and the $\%$ TRPV4 positivity in the same IVDs (Fig. 2d), suggesting that TRPV4 expression may increase in IVD degeneration.

\section{Osmotic regulation of TRPV4 expression}

Cell culture experiments were performed to investigate if the altered TRPV4 expression observed in the organ culture model was a direct result of cellular exposure to TNF $\alpha$ or a secondary change resulting from reduced tissue osmolarity following TNF $\alpha$-induced aggrecan degradation. This study was motivated since prior results demonstrated TNF $\alpha$ exposure increased the amount of aggrecan degradation in this organ culture model (Purmessur et al., 2013; Walter et al., 2015a), and TNF $\alpha$ has also been show to enhance the response of TRP channels in synoviocytes (Kochukov et al., 2009). Bovine NP cells were cultured in monolayer and treated with increasing doses of bovine recombinant 

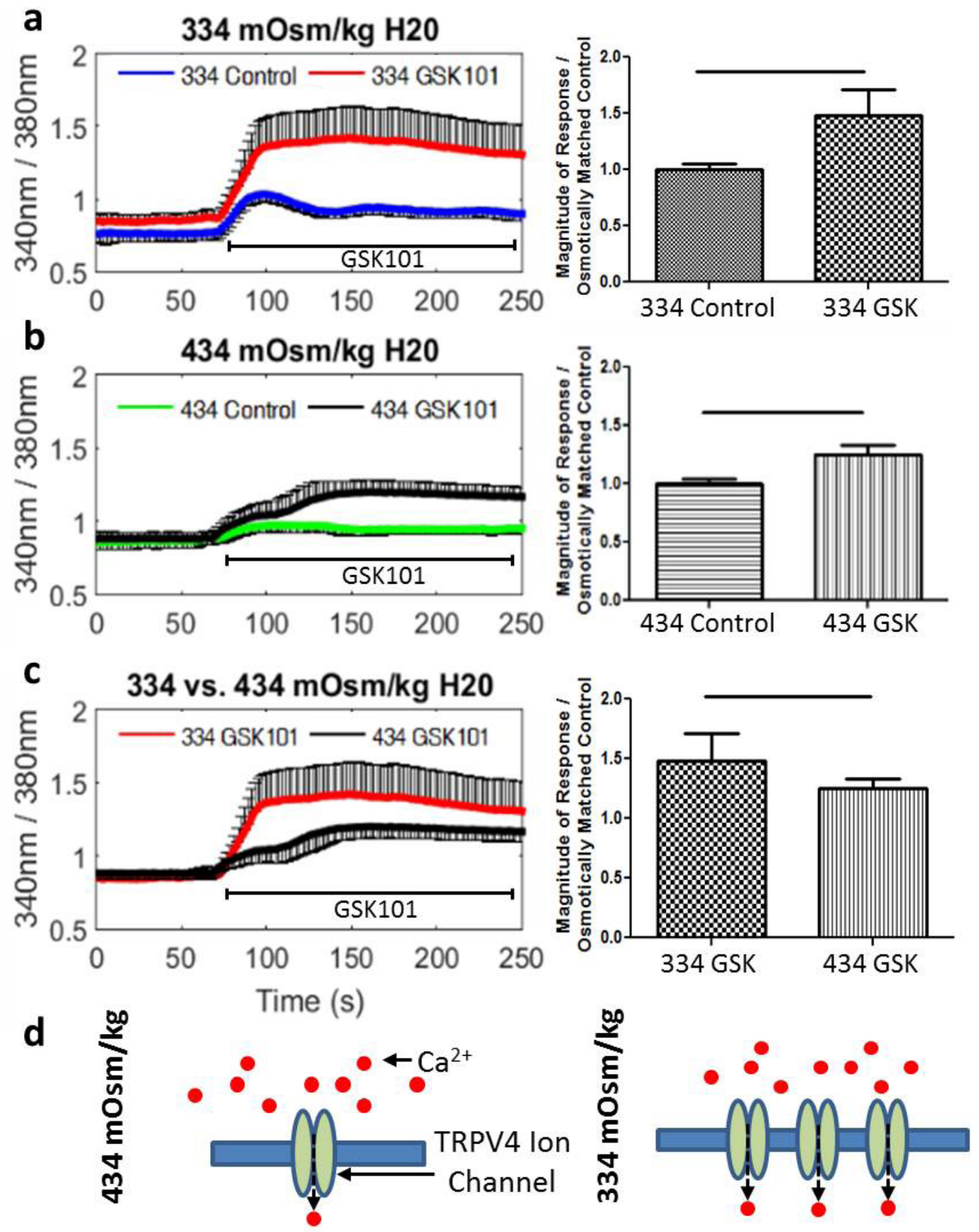

Fig. 4. Elevated TRPV4 expression increased TRPV4 signalling in NP cells. Representative traces and quantification of the calcium response of bovine NP cells treated with or without the TRPV4 agonist (GSK101) after $24 \mathrm{~h}$ of preculture in (a) hypo-osmolar $\left(334 \mathrm{mOsm} / \mathrm{kgH}_{2} \mathrm{O}\right)$ culture medium or (b) physiologic $\left(434 \mathrm{mOsm} / \mathrm{kgH}_{2} \mathrm{O}\right)$ culture medium. (c) Comparison of the calcium responses under different osmolarities for both GSK treated groups. Hypoosmolarity conditions increased the magnitude of calcium flux in cells cultured in a lower osmolarity medium (334 mOsm $\left./ \mathrm{kgH}_{2} \mathrm{O}\right)$. (d) Conceptual model depicting a mechanism for greater TRPV4-mediated calcium flux in hypo-osmotic conditions. $\mathrm{Bar}=p<0.05$.

$\mathrm{TNF} \alpha(0,0.1,1$ and $10 \mathrm{ng} / \mathrm{mL})$ in basal medium that was $334 \mathrm{mOsm} / \mathrm{kgH}_{2} \mathrm{O}$ for $24 \mathrm{~h}$. Following culture, protein was isolated for western blot. TNF $\alpha$ exposure had no effect on the amount of TRPV4 expression at any dose (Fig. 3a); suggesting that the correlation observed in the organ culture model was not a causative relationship. Bovine NP cells were additionally cultured for 24 or $72 \mathrm{~h}$ in culture medium osmotically adjusted to represent either (i) a physiologic osmotic environment ( $\left.434 \mathrm{mOsm} / \mathrm{kgH}_{2} \mathrm{O}\right)$ (Johnson et al., 2014) or (ii) a degenerated IVD (334 or $234 \mathrm{mOsm} /$ $\mathrm{kgH}_{2} \mathrm{O}$ ). Western blot demonstrated that cells cultured in a hypo-osmotic environment ( 334 and $234 \mathrm{mOsm} / \mathrm{kgH}_{2} \mathrm{O}$ ) significantly increased the amount of TRPV4 expression after both 24 and $72 \mathrm{~h}$ relative to the physiologic osmotic environment within the IVD (Fig. $3 \mathbf{b}$ and $\mathbf{c}$ ). 

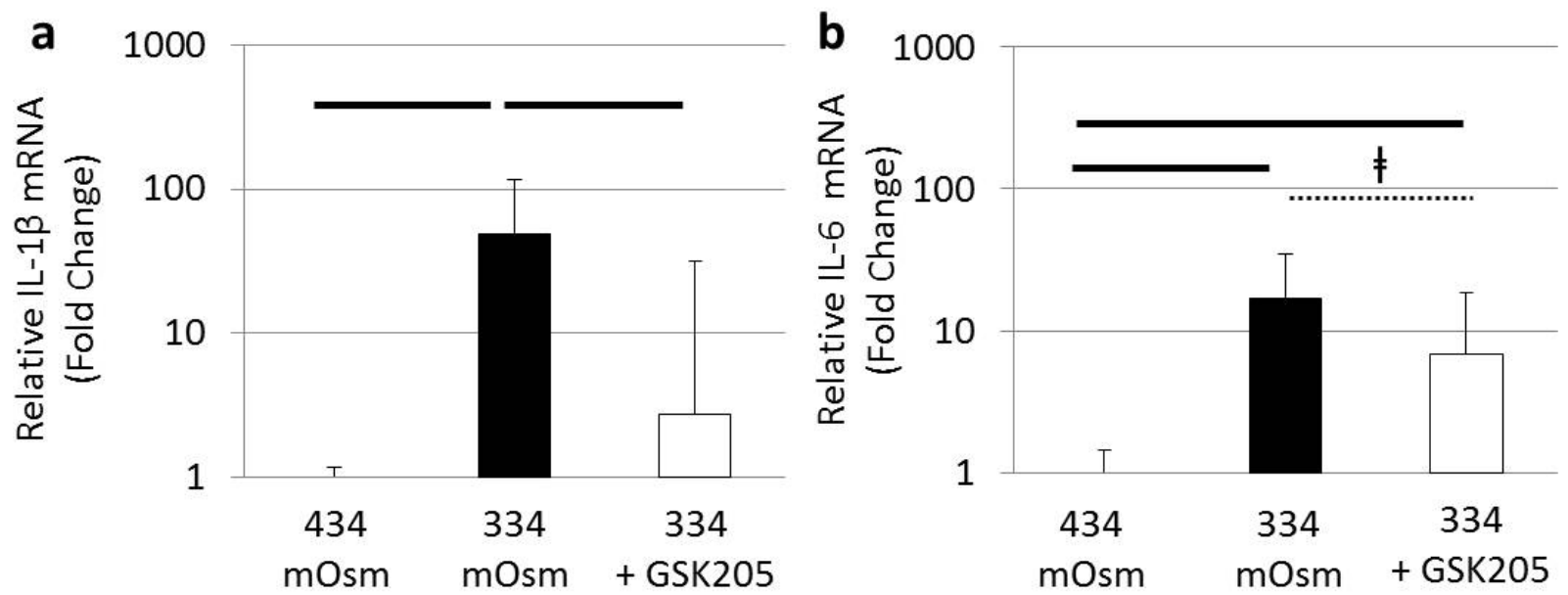

Fig. 5. TRPV4 signalling mediates IVD cell expression of pro-inflammatory cytokines. Gene expression for the pro-inflammatory cytokines (a) interleukin-1 $\beta$ and (b) interleukin-6 were increased after $24 \mathrm{~h}$ under hypo-osmotic conditions (334 mOsm/ $\mathrm{kgH}_{2} \mathrm{O}$ ). TRPV4 inhibition using the TRPV4 antagonist (GSK205) decreased the proinflammatory gene expression indicating that TRPV4 signalling was an important regulator of pro-inflammatory gene expression in the IVD. $\mathrm{Bar}=p<0.05$ and $\mathrm{t}=p<0.1$.

Elevated TRPV4 expression increased calcium flux Intracellular $\mathrm{Ca}^{2+}$ measurements were carried out to test if an increase in the protein expression of TRPV4 resulted in an increased calcium flux following exposure to the TRPV4 specific agonist GSK101 (5 nM). In order to alter TRPV4 expression, bovine NP cells were pre-cultured for $24 \mathrm{~h}$ in osmotically controlled culture medium representative of the tissue osmolarity of either a healthy (434 mOsm $/ \mathrm{kgH}_{2} \mathrm{O}$ ) or degenerated (334 mOsm/ $\mathrm{kgH}_{2} \mathrm{O}$ ) IVD. Monitoring of the intra-cellular calcium concentrations demonstrated that treatment with GSK101 significantly increased the intracellular calcium in cells pre-cultured in both $334 \mathrm{mOsm} /$ kgH $\mathrm{O}_{2}$ (Fig. 4a) and $434 \mathrm{mOsm} / \mathrm{kgH}_{2} \mathrm{O}$ (Fig. 4b) compared to their osmotically matched control. When comparing the magnitude of the calcium flux following TRPV4 activation in cells pre-cultured in different osmolarities, GSK101 treatment resulted in a significantly greater calcium flux in cells pre-cultured in hypo-osmotic conditions ( $334 \mathrm{mOsm} /$ $\mathrm{kgH}_{2} \mathrm{O}$ ) compared to cells pre-cultured in physiologic osmolarity conditions $\left(434 \mathrm{mOsm} / \mathrm{kgH}_{2} \mathrm{O}\right)$ (Fig. 4c). There was no difference in amount of cells responding to GSK101 in either osmotic condition. Results suggest that increased TRPV4 expression resulting from reduced osmolarity lead to increased TRPV4 mediated calcium signalling.

\section{TRPV4 inhibition reduces osmotically induced pro-} inflammatory cytokine gene expression

To investigate the direct effects of TRPV4 signalling on pro-inflammatory gene expression, bovine NP cells were pre-cultured for $24 \mathrm{~h}$ in physiologic (434 mOsm/ $\left.\mathrm{kgH}_{2} \mathrm{O}\right)$ and hypo-osmotic $\left(334 \mathrm{mOsm} / \mathrm{kgH}_{2} \mathrm{O}\right)$ conditions and treated either with or without the TRPV4 specific antagonist GSK205 $(10 \mu \mathrm{M})$ for $24 \mathrm{~h}$. Gene expression for IL-1 $\beta(p<0.05)$ and IL-6 $(p<0.05)$ was increased in cells cultured in hypo-osmotic conditions (334 $\mathrm{mOsm} / \mathrm{kgH}_{2} \mathrm{O}$ ) compared to physiologic osmolarity $\left(434 \mathrm{mOsm} / \mathrm{kgH}_{2} \mathrm{O}\right)$ (Fig. 5). Inhibition of TRPV4 significantly reduced/ prevented the increase in IL-1 $\beta$ gene expression $(p<0.05)$ and had a similar, although non-significant, inhibition of IL-6 gene expression $(p<0.1)$ in response to reduced osmolarity (Fig. 5) indicating that TRPV4 signalling contributed to pro-inflammatory cytokine production by NP cells.

\section{TRPV4 expression in human IVD tissue}

To investigate the potential relevance of changes in TRPV4 expression with human IVD degeneration, immunohistochemistry was performed on one healthy and one degenerated human IVD. Qualitative results demonstrated that an increased expression of TRPV4 in the NP region of the degenerated IVD compared to the healthy NP region (Fig. 6a and b). Reduced alcian blue staining in the NP region of the degenerated IVD suggests a loss of proteoglycan content compared to the healthy IVD (Fig. $6 \mathbf{c}$ and d). Results confirmed that the TRPV4 ion channel was also expressed in human IVDs and suggested that the reduce proteoglycan content may have increased the TRPV4 expression in degenerated IVDs.

\section{Discussion}

This study investigated if changes in osmo-sensation via the TRPV4 ion channel occur within an IVD degeneration model, which factors regulate TRPV4 expression, and the consequence of altered TRPV4 activity on proinflammatory cytokine gene expression. The osmotically sensitive TRPV4 ion channel was shown to be expressed in both human and bovine IVD tissue in NP and AF regions and TRPV4 expression positively correlated with TNF $\alpha$ expression in a bovine IVD degeneration model. In cell culture, TRPV4 expression was increased by reductions in medium osmolarity and were unaffected by exposure to TNF $\alpha$. Elevated TRPV4 expression increased TRPV4 mediated calcium signalling and partially mediated the expression of pro-inflammatory cytokines. Increased 


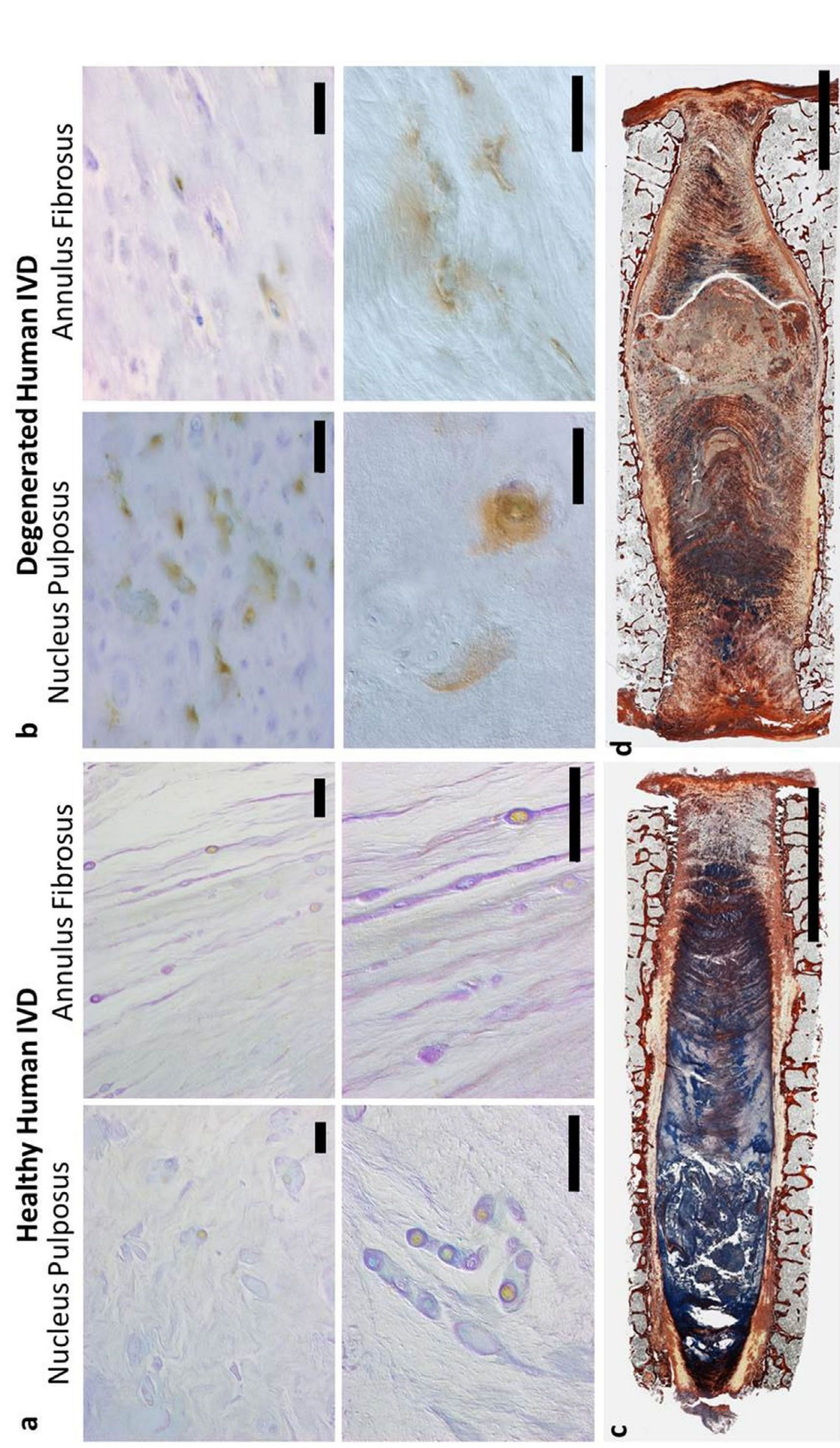

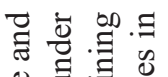

敢

긍 氖

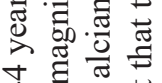

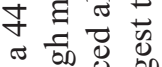

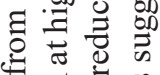

之总苛莺

漹

焉守守

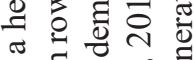

(ิ)

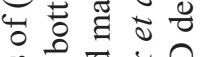

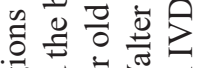

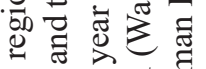

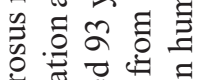

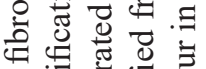

号

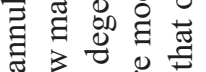

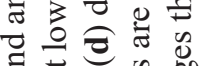

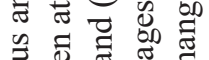

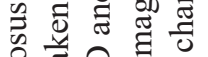

要是早

2.

岂范范

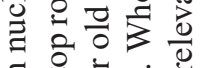

ヨ苛范

存的送

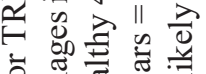

흠

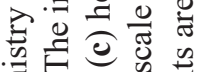

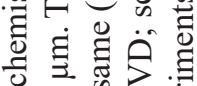

o 0 的它

च $\|$ च

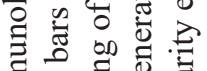

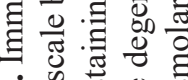

0 is is of

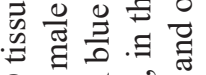

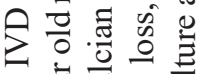

责 ส

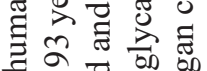

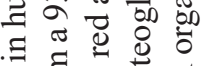

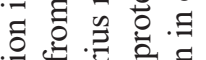

员造它

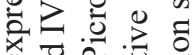

可记

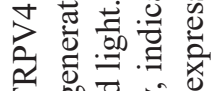

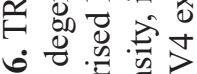

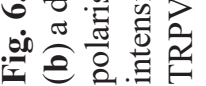


TRPV4 staining intensity and reduced proteoglycan staining in representative degenerated human IVD tissue suggest that the results from the simulated bovine IVD degeneration model may be relevant to human IVD degeneration. Overall, results support the hypothesis that the TRPV4 ion channel is involved in IVD cell osmoregulation and highlights that the TRPV4 ion channel is likely a key mediator in the interaction between inflammation, matrix breakdown and tissue osmolarity.

Changes in tissue osmolarity are known to regulate many cellular functions in IVD cells, such as aggrecan synthesis (Ishihara et al., 1997; Johnson et al., 2014), aquaporin-2 expression (Gajghate et al., 2009) and changes in cellular volume (Maidhof et al., 2014; Pritchard et al., 2002). Interestingly, the TRPV4 ion channel has also been shown to regulate many of these same cellular functions in chondrocytes and other cell types (Becker et al., 2005; O'Conor et al., 2014; Phan et al., 2009) and the presence of TRPV4 within the IVD suggests that it plays an important role in mediating the biologic response to tissue osmolarity. Many of the cellular functions altered by osmolarity are regulated via the TonEBP pathway (Johnson et al., 2014). However, the specific osmo-sensor that increases TonEBP signalling is unknown. This work motivates future investigations to examine whether TRPV4 activation induces TonEBP signalling as an upstream mediator and may help to establish a more complete picture of the signalling response in the IVD following changes in tissue osmolarity.

Tissue osmolarity is known to directly correlate with the fixed charge density of the proteoglycans within the IVD (Urban and McMullin, 1988). As such, the osmotic pressure is reduced as aggrecan and other GAGs are degraded with advancing degeneration (Sivan et al., 2014). Culturing bovine NP cells in a reduced osmotic environment, representative of this advanced disease (334 $\mathrm{mOsm} / \mathrm{kgH}_{2} \mathrm{O}$ ), significantly increased the protein expression of TRPV4 compared to the physiologic osmotic environment ( $\left.434 \mathrm{mOsm} / \mathrm{kgH}_{2} \mathrm{O}\right)$. The osmotic regulation of TRPV4 is consistent with a previous study in chondrocytes that observed elevated TRPV4 expression when cultured in a hypo-osmotic environment (Hdud et al., 2014). However, in contrast, our results suggested that there was a threshold effect where further reductions in osmolarity did not continue to increase TRPV4 expression.

Calcium imaging was used to investigate whether increased TRPV4 protein expression was associated with increased TRPV4 mediated calcium signalling. Results demonstrated that when TRPV4 protein expression was increased, the magnitude of the TRPV4-mediated calcium response also increased. The relationship between TRPV4 expression and activity is to be expected, and these results indicate that IVD cells can dynamically modify calcium flux by modulating the number of TRPV4 ion channels. Increased TRPV4 expression may therefore modify the cellular control system with an amplified cellular response to changes in osmolarity or other stimuli that trigger TRPV4 activation, such as diurnal changes in tissue osmolarity or fluid shear (Wu et al., 2007).

In this study, inhibition of the TRPV4 ion-channel reduced gene expression of multiple pro-inflammatory cytokines (IL-1 $\beta$ and IL-6) induced by hypo-osmolarity. These results implicate TRPV4 signalling in contributing to the inflammatory response of IVD cells and highlight a potential role for TRPV4 in the progression of IVD degeneration. Although additional characterisation is required to fully understand how osmolarity and TRPV4 activity influence the protein expression of these and other pro-inflammatory cytokines, these results are consistent with prior studies, which demonstrated that TRPV4 plays a role in mediating the inflammatory response in other tissues. For example, in lung and adipose tissue, either gene silencing or direct inhibition of TRPV4 significantly reduced the amount of gene and protein expression of multiple pro-inflammatory mediators (Balakrishna et al., 2014; Ye et al., 2012). Additionally, TRPV4 was found to be essential for inflammation evoked pain in the temporomandibular joint (Chen et al., 2013). These results support the hypothesis that increases in TRPV4 expression following a reduction in tissue osmolarity (a hallmark of IVD disease) may contribute to the increased presence of pro-inflammatory cytokines observed in IVD degeneration. This concept is also consistent with studies demonstrating that tissue osmolarity decreases (Urban and McMullin, 1988) and the presence of pro-inflammatory mediators increases (Le Maitre et al., 2007) with advancing degeneration. A similar relationship between reduced osmolarity and elevated pro-inflammatory cytokine expression has been observed in IVD cells and epithelial cells, where exposure to a hypo-osmotic environment increased IL-6 expression (Hubert et al., 2004; van Dijk et al., 2015).

The correlation between TNF $\alpha$ and TRPV4 observed in the inflammatory organ culture model suggests that TRPV4 expression may change with degeneration. This correlation together with the observation that TNF $\alpha$ treatment did not change TRPV4 expression in cell culture suggests that the TNF $\alpha$ did not directly increase TRPV4 in organ culture. $\mathrm{TNF} \alpha$ is known to promote matrix breakdown in the IVD (Purmessur et al., 2013; Seguin et al., 2008; Seguin et al., 2005), and TNF $\alpha$ treatment induced a sufficient amount of matrix breakdown after $6 \mathrm{~d}$ to alter IVD mechanics in a similar inflammatory organ culture model (Walter $e t$ al., 2015a). Aggrecan is the predominate proteoglycan within the IVD and is therefore the key proteoglycan which dictates the osmotic pressure within the IVD (Urban and McMullin, 1985; Urban and McMullin, 1988). This suggests that TNF $\alpha$ induced aggrecan breakdown would reduce the tissue osmolarity within the IVD. This concept of $\mathrm{TNF} \alpha$-induced matrix breakdown reducing the tissue osmolarity together with the observed increase in TRPV4 expression when IVD cells were cultured in a reduced medium osmolarity suggests that TNF $\alpha$ may have indirectly altered TRPV4 expression through increasing proteoglycan degradation, which reduced tissue osmolarity and drove an increase in TRPV4 expression.

A potential relationship between proteoglycan content, tissue osmolarity, and TRPV4 expression is also supported by the qualitative TRPV4 staining on human IVD tissues; which demonstrated a reduced amount of proteoglycan content (alcian blue staining intensity) and an increased TRPV4 expression in the NP region of the degenerated 


\section{a. Inflammation induced Aggrecan Degradation}

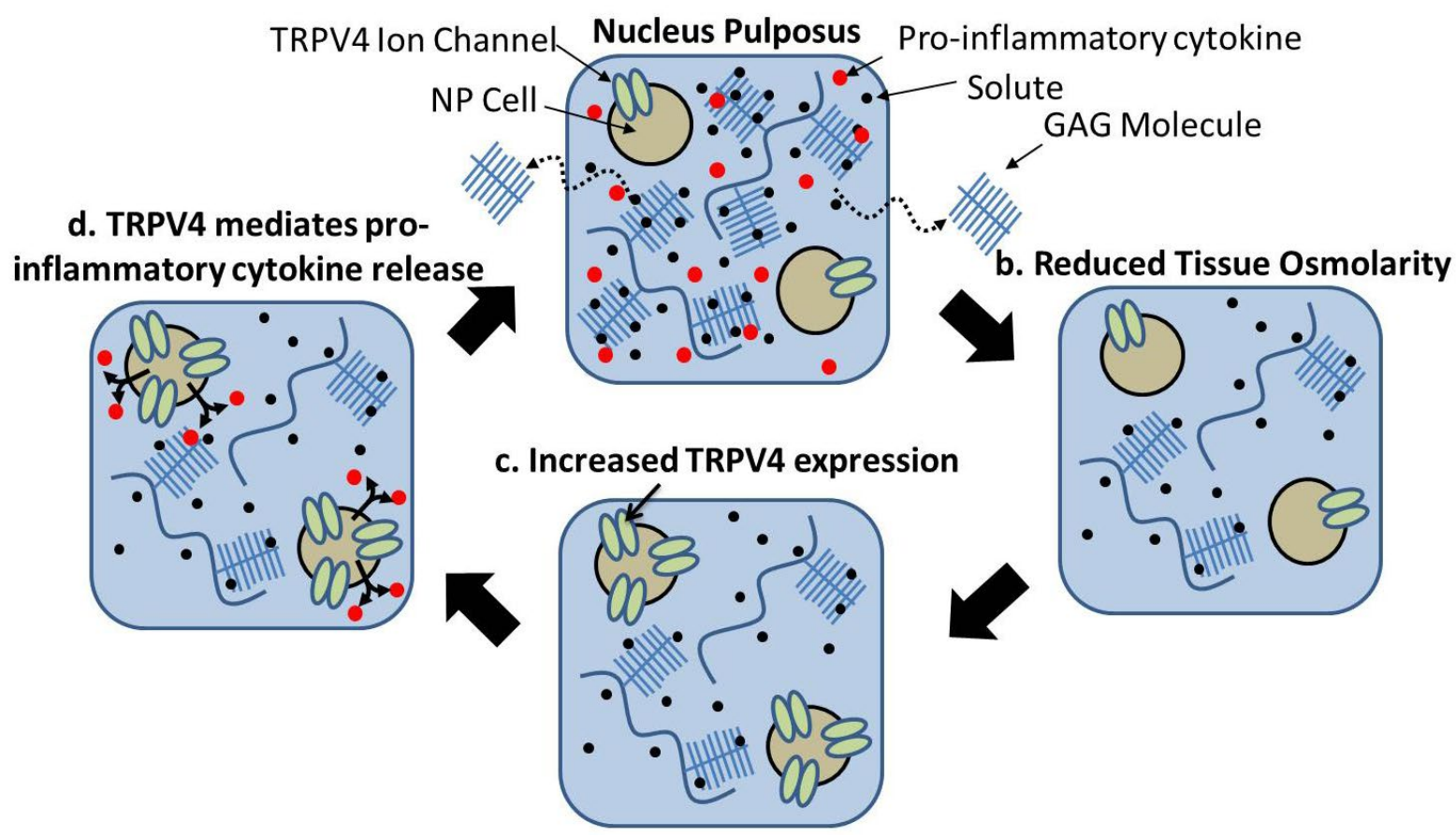

Fig. 7. Proposed hypothetical mechanism for inflammation-induced aggrecan degradation leading to TRPV4mediated pro-inflammatory cytokine production. Schematic demonstrating the potential feedback loop where (a) a healthy nucleus pulposus tissue is exposed to pro-inflammatory cytokines that induce (b) glycosaminoglycan (GAG) degradation and loss which reduces the tissue osmolarity within the NP. (c) Reduced osmolarity stimulates increased TRPV4 expression that (d) mediated expression of additional pro-inflammatory cytokines thereby leading to a potential feedback loop.

IVD compared to the healthy tissue. The small sample size of human tissues motivates additional experiments to fully characterise how TRPV4 expression changes with IVD degeneration and aging and makes it difficult to draw a conclusion; however, the results are consistent with the elevated TRPV4 staining seen in the bovine degeneration model and with the osmotic regulation of TRPV4 expression. Overall, the results, together with the literature, suggest that changes in TRPV4 expression may be relevant to the broader process of degeneration. We propose a new hypothesis that pro-inflammatory cytokine exposure may indirectly alter the expression of the osmosensitive TRPV4 ion channel by inducing degradation which drives an increase in TRPV4 expression and proinflammatory cytokine production (Fig. 7).

The results of this study should be interpreted within the context of the studies limitations. One limitation of this study is related to the use of bovine tissue. Bovine cells and IVDs were used for experiments because they are readily available and their size, composition and metabolism are similar to the healthy human IVDs (Demers et al., 2004; Oshima et al., 1993). This species difference may likely influence the absolute values of tissue osmolarity that the cells experience in-vivo; however, the fundamental cellular mechanism through which cells sense osmolarity are expected to be similar. Also, although no change in TRPV4 expression was observed following TNF $\alpha$ treatment in the investigated osmotic environment (334 mOsm/ $\mathrm{kgH} 2 \mathrm{O}$ ), we cannot rule out the possibility that $\mathrm{TNF} \alpha$ treatment may influence TRPV4 expression in other osmotic conditions. Additional characterisation of a greater array of pro-inflammatory cytokines at both the protein and gene levels is needed to fully understand how osmolarity and TRPV4 activity influences pro-inflammatory cytokine expression. Further assessment of TRPV4 expression in a greater number of human IVDs that include multiple degrees of degeneration is warranted given the small sample size in this study. Despite these limitations, this study demonstrated that the TRPV4 ion channel is present within the IVD and is involved in osmo-sensation which can influence pro-inflammatory cytokine expression.

In conclusion, this work demonstrated that reduced osmolarity, possibly resulting from proteoglycan degradation, can increase TRPV4 signalling and enhance pro-inflammatory cytokine production. These results further demonstrate the TRPV4 ion channel plays a role in mediating the interaction between tissue osmolarity and pro-inflammatory cytokine expression within the IVD and suggests that alterations in TRPV4 expression could play a functional role in disease and are relevant to broader process of degeneration. TRPV4 has been proposed as a therapeutic target in other joint diseases (McNulty et al., 2015) and given the relationship between TRPV4, osmolarity and inflammation demonstrated in this study suggests that TRPV4 may be of therapeutic value for IVD degeneration. 


\section{Acknowledgements}

Research reported in this publication was supported by the National Institute of Arthritis and Musculoskeletal and Skin Diseases of the National Institutes of Health under Award Numbers R01AR057397 and R01AR064157. We gratefully acknowledge Dr Tasos Georgakopoulos for assistance developing the calcium imaging protocol and the Microscopy CORE at the Icahn School of Medicine at Mount Sinai where all the microscopy analysis was performed. We wish to confirm that there are no known conflicts of interest associated with this publication and there has been no significant financial support for this work that could have influenced its outcome.

\section{References}

Abbott RD, Purmessur D, Monsey RD, Iatridis JC (2012) Regenerative potential of TGFbeta3 + Dex and notochordal cell conditioned media on degenerated human intervertebral disc cells. J Orthop Res 30: 482-488.

Balakrishna S, Song W, Achanta S, Doran SF, Liu B, Kaelberer MM, Yu Z, Sui A, Cheung M, Leishman E, Eidam HS, Ye G, Willette RN, Thorneloe KS, Bradshaw HB, Matalon S, Jordt SE (2014) TRPV4 inhibition counteracts edema and inflammation and improves pulmonary function and oxygen saturation in chemically induced acute lung injury. Am J Physiol Lung Cell Mol Physiol 307: L158-172.

Becker D, Blase C, Bereiter-Hahn J, Jendrach M (2005) TRPV4 exhibits a functional role in cell-volume regulation. J Cell Sci 118: 2435-2440.

Chan SC, Ferguson SJ, Gantenbein-Ritter B (2011) The effects of dynamic loading on the intervertebral disc. Eur Spine J 20: 1796-1812.

Chen J, Baer AE, Paik PY, Yan W, Setton LA (2002) Matrix protein gene expression in intervertebral disc cells subjected to altered osmolarity. Biochem Biophys Res Commun 293: 932-938.

Chen Y, Williams SH, McNulty AL, Hong JH, Lee SH, Rothfusz NE, Parekh PK, Moore C, Gereau RWt, Taylor AB, Wang F, Guilak F, Liedtke W (2013) Temporomandibular joint pain: a critical role for Trpv4 in the trigeminal ganglion. Pain 154: 1295-1304.

Demers CN, Antoniou J, Mwale F (2004) Value and limitations of using the bovine tail as a model for the human lumbar spine. Spine 29: 2793-2799.

Gajghate S, Hiyama A, Shah M, Sakai D, Anderson DG, Shapiro IM, Risbud MV (2009) Osmolarity and intracellular calcium regulate aquaporin2 expression through TonEBP in nucleus pulposus cells of the intervertebral disc. J Bone Miner Res 24: 992-1001.

Gawri R, Rosenzweig DH, Krock E, Ouellet JA, Stone LS, Quinn TM, Haglund L (2014) High mechanical strain of primary intervertebral disc cells promotes secretion of inflammatory factors associated with disc degeneration and pain. Arthritis Res Ther 16: R21.

Gilbert HT, Hoyland JA, Millward-Sadler SJ (2010) The response of human anulus fibrosus cells to cyclic tensile strain is frequency-dependent and altered with disc degeneration. Arthritis Rheum 62: 3385-3394.

Gilbert HT, Hoyland JA, Freemont AJ, MillwardSadler SJ (2011) The involvement of interleukin-1 and interleukin-4 in the response of human annulus fibrosus cells to cyclic tensile strain: an altered mechanotransduction pathway with degeneration. Arthritis Res Ther 13: R8.

Goldring MB, Otero M (2011) Inflammation in osteoarthritis. Curr Opin Rheumatol 23: 471-478.

Guilak F, Leddy HA, Liedtke W (2010) Transient receptor potential vanilloid 4: The sixth sense of the musculoskeletal system? Ann NY Acad Sci 1192: 404-409.

Hdud IM, Mobasheri A, Loughna PT (2014) Effect of osmotic stress on the expression of TRPV4 and BKCa channels and possible interaction with ERK1/2 and p38 in cultured equine chondrocytes. Am J Physiol Cell Physiol 306: C1050-1057.

Hubert A, Cauliez B, Chedeville A, Husson A, Lavoinne A (2004) Osmotic stress, a proinflammatory signal in Caco-2 cells. Biochimie 86: 533-541.

Ishihara H, Warensjo K, Roberts S, Urban JP (1997) Proteoglycan synthesis in the intervertebral disk nucleus: the role of extracellular osmolality. Am J Physiol 272: C1499-1506.

Jaalouk DE, Lammerding J (2009) Mechanotransduction gone awry. Nat Rev Mol Cell Biol 10: 63-73.

Johnson ZI, Shapiro IM, Risbud MV (2014) Extracellular osmolarity regulates matrix homeostasis in the intervertebral disc and articular cartilage: Evolving role of TonEBP. Matrix Biol 40: 10-16.

Kochukov MY, McNearney TA, Yin H, Zhang L, Ma F, Ponomareva L, Abshire S, Westlund KN (2009) Tumor necrosis factor-alpha (TNF-alpha) enhances functional thermal and chemical responses of TRP cation channels in human synoviocytes. Mol Pain 5: 49.

Laudier D, Schaffler MB, Flatow EL, Wang VM (2007) Novel procedure for high-fidelity tendon histology. J Orthop Res 25: 390-395.

Le Maitre CL, Hoyland JA, Freemont AJ (2007) Catabolic cytokine expression in degenerate and herniated human intervertebral discs: IL-1beta and TNFalpha expression profile. Arthritis Res Ther 9: R77.

Le Maitre CL, Frain J, Millward-Sadler J, Fotheringham AP, Freemont AJ, Hoyland JA (2009) Altered integrin mechanotransduction in human nucleus pulposus cells derived from degenerated discs. Arthritis Rheum 60: 460469.

Liedtke W, Friedman JM (2003) Abnormal osmotic regulation in trpv4-/- mice. Proc Natl Acad Sci USA 100: 13698-13703.

Livak KJ, Schmittgen TD (2001) Analysis of relative gene expression data using real-time quantitative PCR and the 2(-Delta Delta C(T)) Method. Methods 25: 402-408.

MacLean JJ, Lee CR, Alini M, Iatridis JC (2005) The effects of short-term load duration on anabolic and catabolic gene expression in the rat tail intervertebral disc. J Orthop Res 23: 1120-1127.

Maidhof R, Jacobsen T, Papatheodorou A, Chahine NO (2014) Inflammation induces irreversible biophysical changes in isolated nucleus pulposus cells. PLoS One 9: e99621. 
McNulty AL, Leddy HA, Liedtke W, Guilak F (2015) TRPV4 as a therapeutic target for joint diseases. Naunyn Schmiedebergs Arch Pharmacol 388: 437-450.

Millward-Sadler SJ, Costello PW, Freemont AJ, Hoyland JA (2009) Regulation of catabolic gene expression in normal and degenerate human intervertebral disc cells: implications for the pathogenesis of intervertebral disc degeneration. Arthritis Res Ther 11: R65.

Neidlinger-Wilke C, Mietsch A, Rinkler C, Wilke HJ, Ignatius A, Urban J (2012) Interactions of environmental conditions and mechanical loads have influence on matrix turnover by nucleus pulposus cells. J Orthop Res 30: 112121.

O'Conor CJ, Leddy HA, Benefield HC, Liedtke WB, Guilak F (2014) TRPV4-mediated mechanotransduction regulates the metabolic response of chondrocytes to dynamic loading. Proc Natl Acad Sci USA 111: 1316-1321.

Oshima H, Ishihara H, Urban JP, Tsuji H (1993) The use of coccygeal discs to study intervertebral disc metabolism. J Orthop Res 11: 332-338.

Palmer GD, Chao Ph PH, Raia F, Mauck RL, Valhmu WB, Hung CT (2001) Time-dependent aggrecan gene expression of articular chondrocytes in response to hyperosmotic loading. Osteoarthritis Cartilage 9: 761-770.

Phan MN, Leddy HA, Votta BJ, Kumar S, Levy DS, Lipshutz DB, Lee SH, Liedtke W, Guilak F (2009) Functional characterization of TRPV4 as an osmotically sensitive ion channel in porcine articular chondrocytes. Arthritis Rheum 60: 3028-3037.

Pritchard S, Erickson GR, Guilak F (2002) Hyperosmotically induced volume change and calcium signaling in intervertebral disk cells: the role of the actin cytoskeleton. Biophys J 83: 2502-2510.

Purmessur D, Walter BA, Roughley PJ, Laudier DM, Hecht AC, Iatridis J (2013) A role for TNFalpha in intervertebral disc degeneration: a non-recoverable catabolic shift. Biochem Biophys Res Commun 433: 151 156.

Risbud MV, Shapiro IM (2014) Role of cytokines in intervertebral disc degeneration: pain and disc content. Nat Rev Rheumatol 10: 44-56.

Roughley PJ, Alini M, Antoniou J (2002) The role of proteoglycans in aging, degeneration and repair of the intervertebral disc. Biochem Soc Trans 30: 869-874.

Rutges JP, Duit RA, Kummer JA, Bekkers JE, Oner FC, Castelein RM, Dhert WJ, Creemers LB (2013) A validated new histological classification for intervertebral disc degeneration. Osteoarthritis Cartilage 21: 2039-2047.

Sah RL, Kim YJ, Doong JY, Grodzinsky AJ, Plaas AH, Sandy JD (1989) Biosynthetic response of cartilage explants to dynamic compression. J Orthop Res 7: 619-636.

Salter DM, Millward-Sadler SJ, Nuki G, Wright MO (2002) Differential responses of chondrocytes from normal and osteoarthritic human articular cartilage to mechanical stimulation. Biorheology 39: 97-108.

Seguin CA, Pilliar RM, Roughley PJ, Kandel RA (2005) Tumor necrosis factor-alpha modulates matrix production and catabolism in nucleus pulposus tissue. Spine 30: 1940-1948.

Seguin CA, Pilliar RM, Madri JA, Kandel RA (2008) TNF-alpha induces MMP2 gelatinase activity and MT1-
MMP expression in an in vitro model of nucleus pulposus tissue degeneration. Spine 33: 356-365.

Sivan SS, Wachtel E, Roughley P (2014) Structure, function, aging and turnover of aggrecan in the intervertebral disc. Biochim Biophys Acta 1840: 3181-3189.

Sowa G, Agarwal S (2008) Cyclic tensile stress exerts a protective effect on intervertebral disc cells. Am J Phys Med Rehabil 87: 537-544.

Sowa GA, Coelho JP, Vo NV, Pacek C, Westrick E, Kang JD (2012) Cells from degenerative intervertebral discs demonstrate unfavorable responses to mechanical and inflammatory stimuli: a pilot study. Am J Phys Med Rehabil 91: 846-855.

Torzilli PA, Bhargava M, Park S, Chen CT (2010) Mechanical load inhibits IL-1 induced matrix degradation in articular cartilage. Osteoarthritis Cartilage 18: 97-105.

Ulrich JA, Liebenberg EC, Thuillier DU, Lotz JC (2007) Repeated disc injury causes persistent inflammation. Spine 32: 2812-2819.

Urban JP, McMullin JF (1985) Swelling pressure of the inervertebral disc: influence of proteoglycan and collagen contents. Biorheology 22: 145-157.

Urban JP, McMullin JF (1988) Swelling pressure of the lumbar intervertebral discs: influence of age, spinal level, composition, and degeneration. Spine 13: 179-187.

van Dijk B, Potier E, van DM, Langelaan M, PapenBotterhuis N, Ito K (2015) Reduced tonicity stimulates an inflammatory response in nucleus pulposus tissue that can be limited by a COX-2-specific inhibitor. J Orthop Res 33: 1724-1731.

Walsh AJ, Lotz JC (2004) Biological response of the intervertebral disc to dynamic loading. J Biomech 37: 329-337.

Walter BA, Korecki CL, Purmessur D, Roughley PJ, Michalek AJ, Iatridis JC (2011) Complex loading affects intervertebral disc mechanics and biology. Osteoarthritis Cartilage 19: 1011-1018.

Walter BA, Likhitpanichkul M, Illien-Junger S, Roughley PJ, Hecht AC, Iatridis JC (2015a) TNFa transport induced by dynamic loading alters biomechanics of intact intervertebral discs. PLoS One 10: e0118358.

Walter BA, Torre OM, Laudier D, Naidich TP, Hecht AC, Iatridis JC (2015b) Form and function of the intervertebral disc in health and disease: a morphological and stain comparison study. J Anat 227: 707-716.

Wu L, Gao X, Brown RC, Heller S, O’Neil RG (2007) Dual role of the TRPV4 channel as a sensor of flow and osmolality in renal epithelial cells. Am J Physiol Renal Physiol 293: F1699-1713.

Wuertz K, Godburn K, MacLean JJ, Barbir A, Donnelly JS, Roughley PJ, Alini M, Iatridis JC (2009) In vivo remodeling of intervertebral discs in response to short- and long-term dynamic compression. J Orthop Res 27: 12351242.

Ye L, Kleiner S, Wu J, Sah R, Gupta RK, Banks AS, Cohen P, Khandekar MJ, Bostrom P, Mepani RJ, Laznik D, Kamenecka TM, Song X, Liedtke W, Mootha VK, Puigserver P, Griffin PR, Clapham DE, Spiegelman BM (2012) TRPV4 is a regulator of adipose oxidative metabolism, inflammation, and energy homeostasis. Cell 151: 96-110. 


\section{Discussion with Reviewers}

Reviewer I: In the field of intervertebral disc research, what is the medium osmolarity usually used by researchers for in vitro and organ culture studies? Is there a need to standardise the medium osmolarity for physiological and degenerative culture conditions? Which osmolarity levels are suggested by the authors?

Authors: The reviewer raises the interesting point that medium osmolality in which standard IVD cell and organ culture experiments are conducted is often not osmotically adjusted, unless that is the specific question being investigated. The osmolality of standard cell culture medium is approximately $330 \mathrm{mOsm} / \mathrm{kgH}_{2} \mathrm{O}$ (and can range from 300-350, depending on composition). Inclusion of medium osmolality in the standardisation of "physiological" and "degenerative" culture conditions would be useful for comparison across the field. One consideration for the chosen osmotic condition would be the technique being used and the boundary conditions that are trying to be replicated. For cell culture, the most relevant osmotic condition presumably would be the environment that the cells experience within the tissue, which for healthy IVDs is thought to be a higher osmolality than standard cell culture medium and an osmolality of $400-450 \mathrm{mOsm} / \mathrm{kgH}_{2} \mathrm{O}$ is commonly used. Our results also suggest that an osmolality of $330 \mathrm{mOsm} / \mathrm{kgH}_{2} \mathrm{O}$ or below can initiate a pro-inflammatory response which may impact other measurements. For organ culture, the boundary conditions the culture medium represents may be closer to blood (270-295 mOsm/ $\left.\mathrm{kgH}_{2} \mathrm{O}\right)$, which has an osmolality that is lower than standard cell culture medium. We agree that incorporation of a representative osmotic environment is an important parameter that can differentiate physiologic and degenerated environmental conditions; however, future studies are required to determine the explicit osmolality for each condition.

Reviewer II: The $n$ for the human sample is too small. The osmolarity for a regular cell culture medium is around 300-350.

Authors: We agree that the small sample size in the TRPV4 staining on human tissue is a limiting factor. The intent of the TRPV4 staining on a limited set of human IVD tissue is to highlight that our findings suggesting that a reduced tissue osmolarity resulting from aggrecan degradation may increase TRPV4 expression in bovine IVD tissue and cells may be relevant to the broader human degeneration process. Future studies with greater sample size are required to explicitly examine the effects of aging, injury and degeneration in human IVD tissues and cells.

As discussed with reviewer I, the osmolality for standard cell culture medium is likely different from that experienced by IVD cells in-vivo. This work highlights that the osmotic environment has the potential to influence the cellular response, particularly if examining proinflammatory gene expression or calcium imaging, and should be considered as a variable to control in future experiments.

Editor's note: The Scientific Editor responsible for this paper was Mauro Alini. 